\title{
ARTICLE
}

\section{Occupational exposure recorded before and after new radioprotection regulations}

\author{
Felicia Mihai ${ }^{*}$, Adriana Gheorghiu, Emil Udup and Ana Stochioiu \\ Horia Hulubei National Institute of Physics and Nuclear Engineering - Bucharest,POB MG-6, code: 077125, Romania
}

\begin{abstract}
Radioprotection regulations contained a lot of rules and rational explanations in order to protect occupational exposed workers, patients undergoing radioactive procedures and the environment, too. Since radiation harmful effect has been discovered and until today, the radioprotection rules were changed and improved. In Romania the new radioprotection legislation began to emerge in 2000 and in 2002 the first new rules of radioprotection were issued. This paper presents the new radioprotection legislation effect on the doses recorded by the occupational exposures from research area. In this way, it was calculated the annual collective effective dose and individual doses over the period 1990-2000 for workers who activated in nuclear research laboratories and then compared with the similar radiological statistical data obtained over the period 2001-2010, the number of workers on dose range over the studied period. The mean number of workers who recorded doses over minimum detection limit was about 404 from 843 total number, during 1990-2000 and about 170 from 430 researchers, over 2001-2010. It was observed that the individual and collective doses achieved by the workers in the period 1990-1999 were higher than those recorded after 2000.
\end{abstract}

Keywords: occupational exposure; dose; radioprotection

\section{Introduction}

Ionized radiation and radioactive substances either generated by a natural source or manmade source have many applications since radioactivity phenomenon was discovered. Nuclear research, industry, agriculture and medicine are mainly fields which use the radiation effects. On the one hand the application of radiation coming to the benefit of the people and on the other hand their unrestricted use could be a risk for the population, workers and environment. From these reasons, all the activities such as the operation of nuclear installations, the radiotherapy and medical diagnosis, the management of radioactive waste, the production, transport and use of radioactive material have to follow special standards include rules on radioprotection. Radioprotection rules contain general measures of safety of the occupationally exposed workers, population and environment against harmful effects of nuclear radiation, being mandatory in conducting any nuclear activity. In generally, each country which use radioactive sources in different field of activity has own rules of radiation safety. These radioprotection rules are determined by a number of features of the radiation sources, natural or artificial sources prevailing in that country.

A series of scientific papers present statistics on radiation doses recorded annually by occupational exposed workers taking into consideration collective effective doses distributed on dose ranges for persons which work in the same type of activity [1-4]. In 1999 different dosimetry services from Romania have been captured by the European Organization ESOREX European Study of the Occupational Radiation Exposure in order to centralize data on occupational exposures and to draw an unbiased and complete picture of the exposure situation for workers in Europe. The statistics have been made on each year from 1995 and do not present individual doses recorded over a long period by the same person. In function of doses recorded on radioactivity environmental monitoring and on workers from different nuclear fields, Romanian radioprotection rules have changed. International legislation in the nuclear field has had an important contribution to Romania radioprotection law progress. In Romania, the main activities that use ionizing radiation sources are: industry in nondestructive test, medicine in diagnosis and radiotherapy, education, research, safety and inspection. In this paper it is presented personal monitoring statistics on workers in nuclear research area from Romania, exactly those from "Horia Hulubei" National Institute of Physics and Nuclear Engineering, (IFIN-HH), Romania, monitored by Photo-dosimetry Monitoring Unit (USF), IFIN-HH. The data was recorded over the period 1990-1999, before new radioprotection rules in Romania and during 2000-2010, after applying of the new legislation of nuclear safety.

\footnotetext{
*Corresponding author. Email: fmihai@nipne.ro
} 


\section{Basic principles of the radioprotection legislation in Romania before and after 2000}

Although the benefits of the ionizing radiation use are known with the discovery of radioactivity, in Romania began their operation after 1960. Thus, the first rules of using of ionizing radiation sources and radioprotection of the population, environment and workers were developed in 1976 for the first time by State Committee for Nuclear Energy (CSEN), National Commission for Nuclear Activity Control (CNCAN) nowadays. There were Nuclear Safety Republican Norms published briefly in two volumes referring to rules of radioprotection and mode of work with sources of nuclear radiation [5,6]. From ' 90 and especially from 1999 since Romania began to take part to the ESORES project through dosimetry services, the CNCAN Romanian nuclear authority has adopted the international radioprotection legislation in order to improve the Romanian radiological safety legislation [7-9]. So, in 2000 was issued essential rules of radiological safety [10] and in 2002 CNCAN developed a series of more detailed rules on working with radioactive sources in different fields of application and changed the requirements of the personal dosimeter performances, environmental and personal dose limits, limits of doses in medical applications, how to report and record the radiation doses. In a first stage CNCAN issued seven norms on ionizing radioprotection and the two volumes issued in '76s became Fundamental Norms of Radiological Safety and Norms of individual dosimetry [11,12]. At the end of 2006 CNCAN issued thirty-eight booklets of norms. http://www.cncan.ro/legislatie/norme/norme-de-securitat e-radiologica/. For this work has been taken into consideration essential rules for radiation safety. In Table 1 are presented some radioprotection rules issued before and after 2000 .

Although, thermoluminescent dosimeter (TLD) is used in many countries since ' 80 , in Romania the personal monitoring by TLD was agreed only in 2002 . By new norms, the annual dose limit for a person which is exposed in a radiation field is $20 \mathrm{mSv}$ on year, with a maximum effective dose limit of $50 \mathrm{mSv}$ in any single year, provided that the cumulative effective dose of 5 consecutive years does not exceed $100 \mathrm{mSv}$. After applying the new radioprotection rules the data on radiation doses are reported half yearly and then annually to National Commission for Nuclear Activity Control (CNCAN), Romanian nuclear authority by each service of radiation dosimetry.

\section{Materials and methods}

\subsection{Dosimeter systems}

The personal dosimeter system used in this study was film dosimeter. In the period 1990-1995 the dosimeter film was ORWO, RD 3-4, with an area of $12 \mathrm{~cm}^{2}$ and two photo-emulsion type: low and high sensitive film. From 1996, USF uses for personal doses recording the Agfa "personal monitoring" film that consists of a low speed film (D2) and a very sensitive film (D10) designed to record the $X, \gamma$ and $\beta$ radiations over the dose range $0.1 \mathrm{mSv}-1 \mathrm{~Sv}$. The FB-III-D badge where the film is worn was the same over all studied period. The badge made of Nuclear \& Vacuum, Romania, contains a set of metallic filters of different thicknesses and a window which allows the radiations to pass to the film without being attenuated. The metallic filters are: one $\mathrm{Al}$ filter of $1 \mathrm{~mm}$ thicknesses, three $\mathrm{Cu}$ filters with thicknesses of $0.1 \mathrm{~mm}, 0.5 \mathrm{~mm}$ and $1.00 \mathrm{~mm}$, respectively, and one $\mathrm{Pb}$ filters of $0.4 \mathrm{~mm}$. The badge from plastic (polystyrene, $0.23 \mathrm{~g} / \mathrm{cm}^{2}$ density) has a 1 $\mathrm{cm}^{2}$ area that comes directly in contact with the film, with order to record the doses given by low energy radiation. The range of energy for both dosimeter types is $30 \mathrm{keV}-3 \mathrm{MeV}$. The limits of detection for the first system ORWO, RD 3-4 and FD-III-B badge were 40 mrem for high energy radiation and 20 mrem for low energy and $0.1 \mathrm{mSv}$ for low energy and $0.2 \mathrm{mSv}$ for high energy radiation for the second dosimeter system Agfa and FD-III-B badge.

Table 1. Some radioprotection rules issued before and after 2000.

\begin{tabular}{|c|c|c|}
\hline Criteria & Before 2000 & After 2000 \\
\hline Individual dosimeter device agreed & Film dosimeter & $\begin{array}{l}\text { Film dosimeter, TLD and electronic } \\
\text { dosimeter devices }\end{array}$ \\
\hline $\begin{array}{l}\text { Individual dosimeter performances (limit of } \\
\text { detection) }\end{array}$ & $\begin{array}{l}40 \text { mrem for gamma radiation and } 20 \\
\text { mrem for } X \text { radiation }\end{array}$ & $0.17 \mathrm{mSv}$ \\
\hline Work place monitoring & Active dosimeter & Passive and active dosimeter \\
\hline Annual dose limit for worker & 5 Rem & $20 \mathrm{mSv} /$ year \\
\hline $\begin{array}{l}\text { The reference operating measurement units } \\
\text { for external exposure }\end{array}$ & $\begin{array}{l}\text { Absorbed dose } \mathrm{D},(\mathrm{mGy}) \text {, dose } \\
\text { equivalent (mrem) }\end{array}$ & $\begin{array}{l}\mathrm{Hp}(10) \text { deep dose equivalent, and } \mathrm{Hp}(07) \\
\text { shallow dose equivalent; } \mathrm{mSv}\end{array}$ \\
\hline $\begin{array}{l}\text { Reports of dose to nuclear authority and } \\
\text { Institute of Hygiene }\end{array}$ & $\begin{array}{l}\text { Monthly only if the dose recorded by a } \\
\text { worker is over } 400 \mathrm{mrem} \text {. }\end{array}$ & $\begin{array}{l}\text { Half-yearly and annually by the } \\
\text { collective statistics on number of workers } \\
\text { and type of work }\end{array}$ \\
\hline Dose recorded & Analysis reports; individual books & $\begin{array}{l}\text { Analysis reports; individual books; } \\
\text { electronic recorded; individual data sheet }\end{array}$ \\
\hline
\end{tabular}




\section{Experimental part}

IFIN-HH has a lot of scientific departments which use different sources of radiation. The number of worker monitored by USF was about 843 before 2000 and 430 after 2000. Some departments in addition to research and experimentation activity perform products and services for customers. For this reason workers monitored and statistically presented in this work were grouped as: Research sector, CPR - Radioisotope production center, STDR - waste management and reactor-nuclear reactor used especially in research. All monitored workers have used sealed gamma radiation sources except CPR laboratory which makes ${ }^{131} \mathrm{I},{ }^{190} \mathrm{Ir}$ of different activities and works with open sources. The persons were distributed as follows: 70 in CPR laboratory, 45 in Reactor, 28 in STDR and 700 in Research before 2000. After 2000, 50 persons worked in CPR, 40 in Reactor, 40 in STDR and 300 in Research area. The total number of persons is approximated because many persons have come and gone in nuclear laboratories during 20 years. The film dosimeter records only doses of radiation over natural radiation, being a device used for personal monitoring who work in nuclear field. Until 1997 the personal dosimeters were calibrated by kerma air procedure. The dosimeter calibration was performed in panoramic geometry, so, the doses were assessed in mrem, using the conversion factors (radiation weighting factor in tissue and quality factor). From 1997 the personal dosimeters were exposed to radiation using a PMMA phantom, according to ICRU Report 47 [8] and dose equivalent is assessed in $\mathrm{mSv}$. So, it not used an algorithm for the subtraction of background radiation doses. Before 1997 the MDL-minimum detection limit was 40 mrem and 0.2 mSv after 1997. All doses bellow MDL were considered as zero and for simplification 1 mrem was taken as equal with $0.01 \mathrm{mSv}$. In Figure 1 and Figure 2 are presented the annual collective effective dose over 1990-2000 and 2001-2010 respectively. The annual collective effective dose, $\mathrm{S}$, is given by equation:

$$
S=\sum_{i=1}^{n} E_{i}
$$

where $E_{i}$ is the annual effective dose received by $i-$ th worker and $\mathrm{N}$ is the total number of workers.

The doses of radiation recorded before 2000 are much higher than doses recorded after 2000 especially those from 1990 to 1994 . The average percentage of workers who recorded doses over minimum detection limit was about 47.92\%, during 1990-2000 and about 39.53\% over 2001-2010. Considering the number of monitored persons in each department is found that the highest doses are recorded by staff from CPR not only before 2000 but also after 2000 until 2005.

The dose value registered in CPR Department decreases only over 3 years after the issue of new rules on radioprotection.

The manipulation of the open sources is difficult and

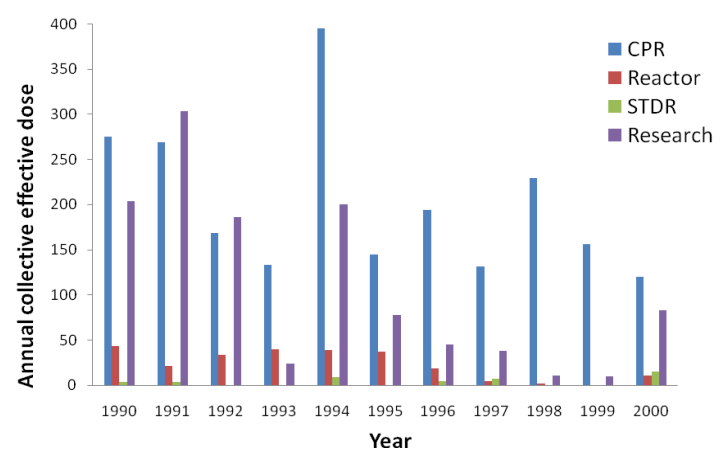

Figure 1. The annual collective effective dose (mSv) over 1990-2000.

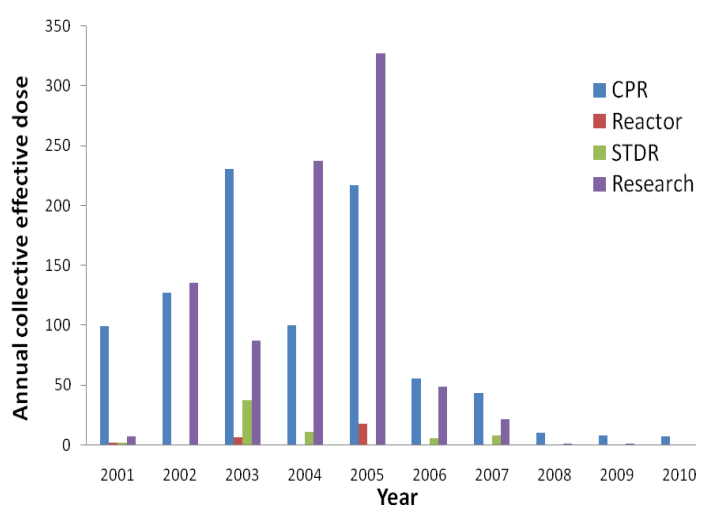

Figure 2. The period 2001-2010 regarding the annual collective effective dose (mSv).

requires a high degree of attention from the operator. In addition to training personnel the implementation of the new legislation of working with open source requires material and financial resource.

Obviously the main factors responsible for the high radiation doses are: the productivity, the requirements for nuclear products, infrastructure and economic from a country at a time. So, in 2004 and 2005 the recorded doses are comparable with a good year of nuclear products before 2000. In the period 2008-2010 the requirements for nuclear products decreased probably due to the economic crisis in Romania.

However, in general we can say that the new rules of radioprotection have a good impact especially on workers from the departments in which to work with sealed radioactive sources. The 2006 and 2007 were good years for nuclear research and products in Romania and nevertheless the doses are smaller than those recorded before 2000. So, implementation of radioprotection rules has an important role in nuclear safety.

The annual collective effective dose characterizes especially radioactivity that staff could record it by job duties in a particular nuclear place. In terms of health for each person it is important the dose accumulated by that person over a long period in a nuclear laboratory. There are presented the number of person on dose range before 2000, Table 2a and after 2000, Table 2b, over a period of 11 and 10 years, respectively.

The doses were calculate by cumulating of the annual doses recorded by one person over the period considered. 
Table 2a. The number of workers on dose range, over 1990-2000.

\begin{tabular}{ccccccccccccc}
\hline Type of & \multicolumn{10}{c}{ Dose range $(\mathrm{mSv})$} & $\begin{array}{c}\text { No workers } \\
\text { with doses }\end{array}$ & $\begin{array}{c}\text { All } \\
\text { workers }\end{array}$ \\
\cline { 2 - 13 } work & $0.2-0.5$ & $0.5-1$ & $1-2$ & $2-5$ & $5-10$ & $10-15$ & $15-20$ & $20-50$ & $>50$ & 113 & 70 \\
\hline CPR & 3 & 6 & 12 & 24 & 15 & 13 & 6 & 22 & 12 & 13 & 45 \\
Reactor & 0 & 6 & 11 & 12 & 5 & 1 & 1 & 0 & 2 & 38 & 28 \\
STDR & 0 & 2 & 4 & 8 & 1 & 0 & 0 & 0 & 0 & 15 & 700 \\
Research & 7 & 43 & 41 & 92 & 29 & 13 & 5 & 7 & 1 & 238 & \\
\hline
\end{tabular}

Table 2b. The number of workers on dose range, from 2001 to 2010.

\begin{tabular}{|c|c|c|c|c|c|c|c|c|c|c|}
\hline \multirow{2}{*}{$\begin{array}{l}\text { Type of } \\
\text { work }\end{array}$} & \multicolumn{8}{|c|}{ Dose range $(\mathrm{mSv})$} & \multirow{2}{*}{$\begin{array}{l}\text { No workers } \\
\text { with doses }\end{array}$} & \multirow{2}{*}{$\begin{array}{c}\text { All } \\
\text { workers }\end{array}$} \\
\hline & $0.5-1$ & $1-2$ & $2-5$ & $5-10$ & $10-15$ & $15-20$ & $20-50$ & $>50$ & & \\
\hline CPR & 1 & 7 & 6 & 5 & 9 & 6 & 17 & 3 & 54 & 50 \\
\hline Reactor & 0 & 4 & 1 & 2 & 0 & 1 & 0 & 0 & 8 & 40 \\
\hline STDR & 0 & & 2 & 5 & 2 & 0 & 0 & 0 & 9 & 40 \\
\hline Research & 0 & 5 & 11 & 39 & 21 & 10 & 11 & 0 & 97 & 300 \\
\hline
\end{tabular}

The persons which have registered similar doses were distributed in the same range of doses. CPR laboratory that has double activity, research and production, exposes workers to radioactivity increased. Generally, in CPR laboratory the same persons work not only in research area but also to honor the economic contracts relating to production of short-lived radioisotopes used in medicine for diagnostic or radiotherapy. This fact leads to an increase of the $\mathrm{Hp} \mathrm{(10)} \mathrm{dose} \mathrm{for} \mathrm{these}$ persons.

In Figure 1 and Figure 2 refer to collective dose on each year from 1990 to 2000 and 2001 to 2010 , respectively. In Table $2 \mathrm{a}$ and Table $2 \mathrm{~b}$ refer to the dose accumulated by one person during 11 years and than 10 years.

The annual collective effective doses are higher for CPR and Research Laboratories than other monitored laboratories, especially for 1990-2000 than 2001-2010 and thus, the number of people who have recorded higher doses over the limit of detection and distributed on dose intervals is higher for CPR and Research laboratories and higher in the first period 1990-2000 than in the second period from 2001 to 2010 .

From different reasons after 2000 the number of persons which worked in nuclear research and monitored by USF decreased considerably. Some persons have been working in the same nuclear place since 1990.

\section{Conclusion}

Generally the monitored workers have recorded doses below the radiation dose permitted by the rules of radioprotection. The nuclear laboratories in that to work with open source, the workers are exposed to high doses of radiation. Compliance and implementation of radioprotection rules in working with open source of radiation are more difficult than in case of sealed sources. The highest doses are registered in departments that include besides research activities and nuclear products and services. The demand of nuclear products leads obviously to increasing of the radiation risk. From data presented in this paper the doses recorded before new radioprotection rules application are higher than those recorded after 2000. The full implementation of radioprotection rules lead to increased safety in work with radioactive sources. Regarding individual doses over a long period of working in nuclear research field these are in limit of the doses allowed by radioprotection laws.

\section{References}

[1] S. Economides, P. Tritakis, E. Papadomarkaki, E. Carinou, C. Hourdakis, V. Kamenopoulou and P. Dimitriou, Occupational exposure in Greek industrial radiography laboratories (1996-2003), Radiat. Prot. Dosim. 118 (2006), pp. 260-264.

[2] M.B. Martins, J. G. Alves, J. N. Abrantes and A. R. Roda, Occupational exposure in nuclear medicine in Portugal in the 1999-2003 period, Radiat. Prot. Dosim. 125 (2007), pp. 130-134.

[3] B.N. Gregori, S.B. Papadopulos, M. Saravi and J.J. Kunst, Argentine intercomparison programme for personal dosimetry, Radiat. Prot. Dosim. 125 (2007), pp. 98-100.

[4] A. Jabeen, M. Munir, A. Khalil, M. Masood and P. Akhter, Occupational exposure from external radiation used in medical practices in Pakistan by film badge dosimetry, Radiat. Prot. Dosim. 140 (2010), pp. 396-401.

[5] State Committee for Nuclear Energy, Health Ministry, National Council for Water, Republican Nuclear Safety Norms. Norme Republicane de Radioprotectie, Bucharest, Romania, (1976), pp. 7-99.

[6] State Committee for Nuclear Energy, Health Ministry, National Council for Water, Republican Nuclear Safety Norms. Operating mode with nuclear radiation sources, Bucharest, Romania, 11-115 (1976).

[7] ICRP, General Principles of Monitoring for Radiation Protection of Workers, Pergaman Press, Oxford, ICRP Publication 35 (Annals of the ICRP, Vol. 9, No.4), (1982).

[8] ICRU, Measurement of Dose Equivalents from External Photon and Electron Radiation, ICRU Report 47, Bethesda, Marybud, (1992). 
[9] IAEA, Basic Safety Standards for Protection Against Ionizing Radiation Sources, Safety Series No. 115, IAEA, Vienna, (1996).

[10]Monitorul Oficial al Romaniei, Norme Fundamentale Privind Securitatea Radiologica, No 404 bis, (2000).

[11]National Commission for Nuclear Activities
Control, Fundamental Norms of Radiological Safety, NSR-01, Bucharest, Romania, (2002), pp. 1-148.

[12]National Commission for Nuclear Activities Control, Norms on Radiological Safety. Norms of Individual Dosimetry, NSR-06, Bucharest, Romania NSR-06, (2002), pp.1-104. 